\title{
Political / Power Structure and Vulnerability to Natural Disaster in North Western
}

\author{
Pakistan \\ * Muhammad Ishaq, PhD Scholar \\ ** Inam Ullah Leghari, Assistant Professor
}

\begin{abstract}
The current study tries to explore the link between the power structure and vulnerability to natural disasters like flash floods in Chitral, situated in the northwest of Pakistan. Flash floods are common in northern areas of Pakistan because of the steep nature of the terrain, melting of glaciers, and torrential rain in summer. In the Chitral district, its effects are adverse because of dwelling patterns and scarcity of safe locations for living. Ethnographic research tool, participant observation, in-depth interviews, informal talking, were used to understand the relationship between the power structure/ political structure in the district and vulnerability to flash floods and its aftermaths. Descriptive analysis technique has been used to analyze the ethnographic data. In princely state lower status people used to be compensated through land. In the locale of research, situated in upper Chitral, it has been observed that most of the low-status families are living in marginal locations making them vulnerable to flash floods. 2013 and 2015 flash floods data in the village of Reshun shows that majority of the affected families belong to low-status groups. Mainly it is the vulnerable location where these families are living. These families were not only affected more than upper-status people living in the village but the post-disaster situation was also worse for them in comparison to other parts of the village.
\end{abstract}

Keywords: Vulnerability, Power/ Political Structure, Northern Pakistan, Chitral, Flash Floods Introduction

Historically, disasters have been discussed and connected with the extreme events that happen in nature. Though it can't be denied that some areas are more hazardous than others, but the question is why humans choose to live in hazardous areas. A paradigm shift in disaster research happened where vulnerability to natural hazards remains the focus (Hewitt, 1983; Sokefeld, 2012). Because of this paradigm shift in disaster research, social scientists started theorizing disasters in the context of vulnerability.

The most comprehensive model to explain vulnerability and its root causes is "Pressure and Release (PAR) model. This model was first released in 1994 by Piers Blaikie et al. Hazards are the potential threats that can turn into a disaster if the population is vulnerable. Mainly its political and economic systems that are broadly responsible for vulnerability. Limited access to political and economic sources is the root causes of vulnerability. (Blaikie et al, 2004). Groups with less or no share in power usually are also economically weak. Such groups usually live in marginal areas that are not safe for living like flood-prone areas, dangerous and unstable slopes, as well as marginal urban locations which are usually not useful or less important for people or groups who hold a major share in the power structure as well as are controlling economy((Blaikie \& Brookfield 1987; Wisner 1976, 1978; Blaikie et al, 1994) Specific instances of such vulnerabilities are people or groups who live in hazardous conditions and not in a position to afford safe. This leaves individuals and groups of people no resilient to shocks bigger or smaller. Any kind of shock can easily jeopardize the survival as they are unable to coup with it. According to this analysis, one big reason is poverty. They are vulnerable because they are poor and poverty is the result of unequal share and discrimination within the political economy. The dwelling pattern and livelihood pattern are historically vulnerable because of discriminatory practices (Blaikie et al, 1994). This point of analysis is very much relevant to the

* Quaid-e-Azam University, Islamabad, Pakistan Email: isak700@gmail.com

** Department of Anthropology, Quaid-e-Azam University, Islamabad, Pakistan

Email: inam.leghari@qau.edu.pk 
argument that I go with. Groups are dwelling in flood-prone areas in Chitral. Vulnerable groups have historically very limited share in the political structure and economy of the region.

There are criticisms of such circular interrelationships between economy, power structure, and vulnerability. Neil Middleton and Phil O'keefe write about vulnerability and its relationship to power structure. The basic reason that is responsible for differential exposure or vulnerability to hazards and disaster is political conditions prevailing on local and global levels. Unequal distribution of power creates unequal social conditions. Thus unequal social conditions create differential vulnerability to disaster (Middleton \& O'Keefe, 1998; Sökefeld, 2012). For them, political structure and power distribution is the main cause for unequal vulnerability to the same hazards and disasters. If we understand the context in which the population lived it will be easy to understand vulnerability. Disasters are historical events and their root is embedded in history (Oliver-Smith, 1979, 1986; Lees \& Bates, 1984; Bankoff et al. 2004).

\section{Power/ political structure and land ownership in Chitral and Reshun}

Chitral society remained divided into groups with unequal status. Out of four categories, the top ranks belong to katore, rulers of Chitral. The second position belongs to adamzade which means true human. They are mostly cousins' descendants of the first ruler of the katore family. Third is peasant farmers known as yuft. The fourth category is the Serf class commonly known as Cheermuzh (Marsden, 2005). I observed that upper-class people still consider their line superior and consider lower classes something below humans.

In the princely state, it was mostly the upper two classes who own the land. The Serf class was given places for construction of houses and in some cases growing crops for own use. The serf classes achieved and retain land through different services they performed to adamzade and rulers in the center (Mulk, 1971; IUCN Pakistan, 2004).In each village in Chitral serving classes have dwellings that are separate from other classes. In general, it is known as ghalamusandeh which literally means the hamlet of the slaves though it is considered inappropriate to talk about the serfdom or who remained serf as it is considered derogatory and rude to talk about others in such a disrespectful way (Marsden, 2005).

In Reshun there are three such hamlets where serving classes are residing. In the village lordly families, Khushahmade, khushwaqte, and Zondra, and few households who remained part of the administration, Hakim, in princely state are served in different capacities by serfs living in the three hamlets, Panandeh, Batikandeh and Golguch. These hamlets are situated in a relatively marginal location. It is in the middle of two mountains and a stream is running in the middle of it. In 2013 and 2015 most of the affected houses from the flash flood are from these three hamlets which are discussed in detail in the latter part of the paper.

\section{Vulnerability in Chitral}

Because of mountainous terrain and the volatile nature of mountains and soil, only a few places in district Chitral can be considered safe from natural hazards. Most of the population is living in $U$ shaped valley that is drained by the Chitral River (Asif Khan, 2013). Climate change and temperature rise have increased the vulnerability of the population. Limited resource base economy is limiting choices for people of Chitral to cope with any kind of hazards like flash floods.

Chitral district is situated on the Hindu Kush range which is famous for frequent seismic activities. 2008 and 2015 earthquakes which were recorded on the rector scale as between 7.5 to 7.8 jolted the region and caused huge destruction. Flash floods, earthquakes, landslides, and avalanches are all types of natural hazards that are occurring in the district with varying frequencies and are making it difficult for most of the people of Chitral to live without fear of hazards.

Chitral district has been neglected for its remoteness and low population density. Other reasons that make it hard to share equal utilities as the mainstream areas of the province are enjoying is its volatile mountainous structure. Inayatullah Faizi, an educationist and principal of Chitral Model College is critical about the lack of interest of the state about provision and proper use of funds for the development of basic facilities in Chitral. While discussing the lack of government interest in Chitral he said "Chitral has never received its due share. I don't even call Chitral as part of Pakistan. Whenever I go to down districts, to Peshawar, or Islamabad, I tell people I am going to Pakistan. The facilities that people of other districts of Pukhtunkhwa and Pakistan are enjoying are not present here. Even then we are proud of ourselves as we are not suffered from the evils of being extremists or intolerant. People of Chitral are decent. Literacy level is still very high as compared to any other 
district in Pakistan". Arabab from Reshum considers this quality of people of Chitral, being tolerant and not violent, in a different way. He is one of the leaders who were engaged in protests to restore the Reshum mini powerhouse which was destroyed by the 2015 flood. He complains about the nonserious attitude of authorities that they are not providing funds and technical support to restore the facility. People of this area are not violent but it's not good. Whenever such situations arise in down districts where state authorities ignore the voices and rights of people, they come out to block roads and even do violent protests. He thinks it is partly because of the gentle behavior of our people that our basic rights are not fulfilled by the state yet.

An executive of FOCUS, one of the sub-branches of AKDN which focuses on disaster preparedness and relief said; people of Chitral are living in a risky environment. It's not easy to provide basic facilities to everyone here as the terrain is tricky. State institutions never function fully in the district because of many challenges. Only those officers are transferred here who are meant to be punished by high officials or departments. How can one think of an effective response to disasters if the basic state machinery is not fully in place? Moreover, in the recent past, the frequency of flash floods and avalanches increased because of global warming. Two industrial giants, India and China are our neighbors who are making a major share of the factors responsible for global warming. The worst effect of which can be felt on most vulnerable like people of Chitral. The point of discussion in the previous paragraph is that people of district Chitral are vulnerable to natural disasters but because of its remoteness and inability of the state, it can't protect the people of Chitral. Before going to explore internal political/ power dynamics and their relevance to vulnerability, there already exist external factors, national and international, which contribute toward vulnerability of the whole of Chitral district.

Chitral district has been in isolation for most of the history as well as until recently the area used to cut off from the rest of the country for more than five months a year. This isolation kept the district from major infrastructural development. It's not just the above-mentioned respondents who complain about their misfortune. Lack of developmental projects and funds is one reason for the collective vulnerability of the population. James Ferguson calls it "abjection" where a big portion of the population is kept from development. Hegemonic discourses in the $21^{\text {st }}$ century evolved new world geography that has open and mounting frontiers. Interestingly this new world order does not have territorial centers of power as it works virtually and is without static borders (Hardt \& Negri, 2001; Bankoff, 2004). James Ferguson is of the view that this new order is creating spatialized inequality. This is not only continuing to reinforce the existing inequalities but will further deprive a great portion of the population of the promise of development (Ferguson, 1999; Bankoff, 2004). George Bankoff relates such inequalities with power structure on a local and global level that leaves billion of people in geographically less developed zones and areas more vulnerable. Chitral is one example of this inequality which is deprived of proper planning and development by the state institutions.

Incoming section I tried to explore the connection between vulnerability, power structure/ political structure, and disaster in Reshun, Chitral. In recent years in Chitral, there has been a series of flash floods and few heavy earthquakes. These flash floods and earthquake has unfolded the social structure of the people that is closely based on political/ power structure of the district.

\section{Materials and Methods}

Primary data for the current study is acquired through qualitative data collection tools dominantly used in anthropological studies. It includes observation, participant observation, non-structured and semi-structured interviews. The researcher spent four months in summer and two months in winter for data collection in the locale. Data is analyzed through descriptive analysis technique which is to develop themes, words, regularities out of stream of data gathered through ethnographic research tools (Flick, 2013)

For secondary data, the researcher visited officials and public offices for relevant data like land records, revenue department, district administration offices to collect data on the land ownership, flash floods in the locale, and lists of affected families. Moreover, literature on the princely state of Chitral, its administrative structure, history, and hierarchy was studied.

\section{Flash floods in Reshum}

Reshum is one of the many villages in upper Chitral where stream is draining the water of huge glaciers. The water is poured by two glaciers at a height of 14000 feet from sea level, collectively 
known as Reshum glaciers are on the back of the stream. The fragile nature of glaciers and its relatively higher elevation in comparison to the village makes it very dangerous for the people of the village (Hamid, 2013; Rehman, 2015). Data shows that the frequency and intensity of flash floods increased many folds in recent decades as compared to the past. Resultantly flash floods affected an increasing number of communities in downstream riparian areas (Richardson \& Reynolds 2000; Riaz et al. 2014). The same effect has been recorded for Chitral.

Two recent flash floods, 2013 and 2015, caused serious damages in the village of Reshum. Both the flash floods caused damages, human casualties, livestock, houses, roads and bridges, drinking water facilities, irrigation channel heads etc. Most affected people belong to three hamlets, Panandeh, Batikandeh, and Golguch. Houses in these hamlets were mostly built on marginal and vulnerable locations as they can't afford to build houses in safe locations. Data from government departments, the Provincial Disaster Management Authority (PDMA), and the District Disaster Management Unit (DDMU) of 2013 and 2015 indicates that low-status communities are affected more than high-status people as most of the dwellers on vulnerable areas near stream belong to lower status communities and individuals.

Complete lists of affected communities in both the flash floods are further investigated through individual case tracing by cross verifications. To understand the individual cases, their socioeconomic and political background case studies were recorded to further clarify the situation.

\section{Flood at Reshum}

July 312013 was the night of the flood. It was cloudy for two days. Nobody knew that whether it was the rain that caused a flood in Reshum stream or the bursting of glaciers. It was the shepherd who informed people in the village as he was grazing cattle in the Reshun pasture situated up in the valley. In 2013 it was a direct call and torch that informed people in the first hamlet and then it spread all over. Ahmati, who is living on the upper part of the valley near a stream, has a summer place of living up in the mountain when heard the scary sound of the rocks and water, he started efforts to inform the rest. He lost two of his kids, goats, house, and wife sustain injuries. Though the rest of the people in the village rushed frightened towards the mountains to save their lives but they could not save cattle, houses, and crops.

Water channels head and roads were also washed away. Physical contact of deep valley hamlets was lost to village outsiders. Houses were partially and destroyed especially in the Gol area. Sheep and goats were also washed away. According to the District administration, District Disaster Management Unit (DDMU) reports the following damages were confirmed in the 2013 flash flood of Reshum by revenue staff of the state departments.

1. Life loss

2. Livestock perished

3. Damaged houses damaged

4. Damaged irrigation channel heads

02

35 cows, 02 goats

23 fully damaged,16 partially

09

03

05

01

01 kilometer

01 (partially damaged)

$15 \%$ of total village crops.

$03 \%$ of all orchards in the village.

11) Damaged orchards

Source: Distt. Admin/ Chitral District Disaster Management Unit, 2013)

It was the residents of the Gol (stream) area alone whose livestock perished in the 2013 flood. When people heard of a flood, they rushed towards mountains, picked the most precious objects with them as they had very little time to escape in the middle of the night. Families who were living too close to the stream were frightened. They are more vulnerable to floods. Flash flood of low intensity is considered normal in July and August. As mentioned in the previous section, most of the families living in three hamlets of Reshum, Batikandeh, Panandeh, and Golguch belong to clans who were lower in status in the Chitral princely state and likewise were deprived of choosing safe and suitable site for construction of houses. They are living on marginal land that is vulnerable to flash floods. 
It is propagated within the community by Agha Khan Development Network (AKDN) through community meetings in the village that goats are causing damage to glaciers situated in the valleys behind the village. That's why the number of goats is decreasing in the village recently. Cows and goats are making basic source of survival as they eat milk and by-products and in some cases eat its meat, sell it to get cash. Losing cows and goats in flood means a lot in such circumstances for people when they are depending on it for life. All houses, partially and fully, are from the said three hamlets where the vulnerability of the people is higher than the rest of the village. Drinking water is supplied through plastic pipes from a stream water pole constructed near a hydropower station. The supply line was washed by the flood.

Five bridges were constructed to reach the mini powerhouse as well as three hamlets that are inaccessible otherwise. Two mountain ridges cut and block routes to reach the upper hamlets in north and south at different distances from Chitral-Booni road. These bridges were constructed to access these hamlets easily. When flash floods washed away these bridges along with a one-kilometer road, these hamlets were also cut off from the rest of the world through land route. It causes huge inconvenience for the people of these hamlets at times such as flash floods. There is another longer and tougher route for which residents of these hamlets climb nearby mountains that can't be climbed by the elderly, children, and sick people. Things get tougher at times of floods when the routine supply line of food, water, and other routine necessities cuts off. It becomes harder even for relief workers to reach there. The situation in the southern side of Panandeh is even worse as they are completely cut off from the rest of the village. On a social media network, a page is run by a few youngsters of the village where many of the village residents post views. After the flood when the situation was not certain about more episodes of flood and physical communication was cut off, a subscriber post on the said page in the following words

"Although, the volunteers of different outlets are serving the humanity in Reshun and other flood-affected areas very well, but we the people of Reshun Gol are still waiting for someone to knock the doors with at least with a first aid box or with bottles of drinkable water. We haven't witnessed, neither the jackets of Al-khidmat nor that of FOCUS here yet" (The People of Reshun, 2020)

In response to this post, another subscriber of the page respond in the following words

"Sir, for your kind information. I witness the two days visit of focus volunteers with first aid kits and two groups have worked in the restoration of damaged houses. And today we were told not to visit the goal side as a precautionary measure.... you can't expect anyone to visit $u$ in goal today it is life risk. Thank you" (Zakir Ahmed Zakirin, 2020)

Every time after a flood there remain chances of more episodes of flood. Because of these threats relief and recovery for hamlets situated in Gol is always difficult which increases their vulnerability. All these factors make the Gol area much more vulnerable than the rest of the village. Flood destruction and its effects are heavier for the people of these hamlets than the rest of the village.

Recent floods decreased the cultivable land as it brought a mixture of sand, rocks, and stones, spreading it over the nearby land which was used for cultivation. The already marginal land is further devalued by recent flash floods. I observed a few residents who were leveling the land and removing big stones to grow crops but most of them didn't. Akram from Panandeh was waiting for the excavator to come and help him level the land which is full of heavy stones after the 2015 flood.

Fruit trees on both sides of the stream belong to families living in the three hamlets near the stream. Heavy trunks of some walnut trees are still visible in the debris of the flood. Walnut, mulberry, and apricot make an important portion of the cold winter diet in Chitral. Losing these trees is also a big loss for the residents of Gol.

\section{Flash Flood}

In 2015 another flash flood hit Reshun village. This flash flood was stronger in intensity than the 2013 flash flood. Damages to infrastructure were more than that of the 2013 flood. It happened in the middle of the night but people were mostly awake especially those who were near the stream as it rained on that day. People were expecting a flood. Ibrahim, a resident of Panandeh said while talking about the night of the flood. "A huge rock, the rock which is bigger than 20 square feet room is still lying on one side of the stream with smaller rocks scattered around it, hit the already existing rock which was brought there by the previous flood. This collision was so heavy that produced a loud sound just like a bomb. The collision also created light. Everyone was frightened because nobody 
knew the exact intensity of the flash flood. Whenever a flash flood comes, it spread a heavy air ahead of water running faster than water. I have seen it myself. It must be produced by a heavy flow of water and other material. The air flows faster and it's so strong that it does fell trees and everything in its way. Heavy sound produced by rocks collision spread fear in the village. I was thinking the high mountain might fall due to heavy flood. Everyone ran toward the mountain as it was the only safe place in the village at least for the people of streamside hamlets. We had evacuated our cows and goats. Because of the 2013 experience and rain in day time most of the streamside hamlets' residents were shifted to mountain base and were lying in open sky. But we could not help protect our houses. I was telling my friends in the lower part of the village to get protected through cell phones. It was within a minute that flash flood reach to the last hamlet of the village after the heavy sound. Residents of the Gol (stream) area remain more cautious during the possibility of flood as compared to the rest of the village. It always hit us and seldom has it reached outside its limits. This is one reason residents of other hamlets remain calm and don't take necessary precautions during flood months as compared to Gol residents".

According to District Administration and District Disaster Management Unit (DDMU) report following damages happened to the village Reshum.

1) Mini power house damaged at Reshum

2) Bridge on Chitral-Booni road washed away

3) Reshum powerhouse road washed away again

4) Five irrigation water channel heads completely washed away

5) All drinking water pipes damaged and washed away

6) 98 houses are fully damaged while around 50 partially damaged

Source: Distt.Admin/ Chitral District Disaster Management Unit, 2015

This powerhouse is providing electricity to half of the Chitral district mostly to the upper Chitral. This was constructed in the 1980s and since then it is providing electricity to the said areas on discount rates. The voltage of the national power grid remains very low because of the high distance. It provides power only to Chitral city. In Chitral power is generated mostly through small turbines built on water channels mostly constructed on small streams. Powerhouse at Reshum is the biggest of its kind in the district. The maximum capacity of the facility was 4.5 megawatt at the time when it was constructed.

Residents of Reshum as well as upper Chitral were hopeful in the initial days after the flood that government would fix the facility soon. When after months there was no sign to fix the powerhouse, residents of upper Chitral started agitation in the shape of a movement known as Tehreek I BahaliyeBijligharReshun (movement of the restoration of Reshun powerhouse).

Powerhouse of Reshum provided a platform for local political figures to speak against the authorities and political parties in power. All political figures of the district put their share to win sentiments of the people as it remained a hot issue for the people of upper Chitral for more than three years. This is a good example of how the disaster-hit people can organize their power to protest and pressurize the government officials.

As the intensity of the flood was high, it washed away the bridge situated on the stream in Reshun. Similarly, flood washed away the road that is the only route of the three hamlets to the main road. After the 2013 flood, the said road was destroyed but restored temporarily by the Communication and Work (C\&W) department. 2015 flood washed it completely. Summing it up, vulnerable road structure left the population in three hamlets further vulnerable because of no access to the main road.

Falling rocks in an earthquake increases the risk for Gol residents. In the 2013 flash flood, it was only residents of the three hamlets, Panandeh, Batikandeh, and Golguch, who were affected. In the 2015 flash flood, it was again residents of these hamlets who are more affected than the other parts of the village. As the 2015 flash flood was more severe than the 2013 flood it also affected few houses in the western part of the village.

Out of a total of 98 fully damaged houses, 30 damaged houses are those which were affected by the 2013 flood. In the 2013 flood, 39 houses were affected. All of them were in three hamlets, Panandeh, Batikandeh, and Golguch. In 2015 flood 30 of these hoses are damaged fully again while 9 houses are not affected. 5 out of 9 households shifted to a nearby hamlet known as Greemlasht, about two kilometers from Reshun. They have recently purchased land in that village. After the 2013 flood, 
these families constructed houses on the purchased land and shifted there. Remaining four households shifted near a mountain that is safe from flash floods but vulnerable in case of earthquake. In the 2015 flood, these families went unaffected. All the affected thirty a household had reconstructed houses again on the same place where they were living before 2013. They have limited choices as they don't have safe places to be shifted nor can they purchase land anywhere else as some families did to avoid the disaster.

Out of 98 fully damaged houses 86 are from three hamlets situated near the stream discussed previously. These houses belong to Panaye, batik, and other residents of Golguch. All of them belong to lower-status people who are living in vulnerable locations. Most of them still live in the same place. Many of them try to stay away from their houses at night in summer to avoid flash floods. It is again a risk to leave the property without anyone inside. Some have erected prefabricated shelter houses provided by relief agencies and NGOs on mountain or someone else land. They are mostly one-room houses. In summer when the probability is high, they stay there. In Panandeh young man told me about the skill of how to unlock the house's teen ceiling when it's a danger of flood. "We can save the top of houses in this way at least. It is risky and flood can also get us if we could not unlock the top of the houses and run with it to the safe place, near the mountain. Our life is always on the run in summer. Sometimes we remove the top of the houses and flood doesn't happen. Sometimes it is so fast that nobody can dare go near it and it washes away everything"

\section{Case studies}

In this section, selected cases are written from three hamlets to share individual experiences in the village and with the flood. These life stories and experiences of the people are selected based on damaged houses in the 2013 and 2015 floods. It is pertinent to mention here that no case is similar to others as everyone has his own experience of flood though it brings havoc on all.

\section{Case study 1}

Ashraf khan head of one such household who is affected both in the 2013 and 2015 flash floods. He is a resident of Golguch, one of the three severely affected hamlets of the village. His forefather migrated from Wakhan. Wakhi people are migrants from the border area of Afghanistan and Pakistan, a strip that is stretched. In Golguch hamlet of Reshum few families claim to be migrated from Wakhan. Since Chitral was a princely state, these migrants were placed in lower ranks. In Golguch there are 11 Wakhik families. The lands that they have constructed houses on are given to them as a reward for their services to poster the children of high-status families in the village.

"In Golguch we are exposed to flood more than anyone in the village. My house was fully damaged in the 2013 flood. The bridge on the road that leads to the powerhouse stopped the flow of flood and flood water reached my house as it is on the verge of stream and road. We rushed towards the mountain on the back of the house. It was dark but my house was visible. I can't explain the situation. Children and women were crying. We were gathered at one place, my family and four other families in my neighborhood. We could not save anything as it was sudden. We were trapped by flood as it had washed away the bridges and only rout to main Chitral-Booni road. In front it was a flood and at the back mountain. We all spent one week in open. FOCUS employees, Agha Khan Development Network (AKDN) special agency for disaster, reached us through a mountain route. They provide tents, drinking water, and food. I send women and children to a relative house. They live there for two months. Meanwhile I was busy reconstructing my house which was full of mud and roof was fallen on the ground from one side. It took me six months to rebuild my house. I don't have a place.

In 2015 it happened again. This time it was severe and it washed away everything. I rebuilt it again in the same place. It took me one year to complete this time. I have no other place to live or construct my house. In summer we remain on alert as we are in a very dangerous location. One of my cousins who are also affected by the flood built his house very close to the mountain. It is dangerous too for rocks can fall on the tin roof and can kill them in earthquake"

\section{Case study 2}

Sher Muhammad is another victim of the 2013 and 2015 floods. He is a contractor and takes contracts from big contractors to construct small portions of big projects. He wants his kids to complete higher education and start jobs away from here. He doesn't want his kids to waste here as there are fewer opportunities for educated people and it's not suitable for living. Sher Muhammad is active in case of pay (local term used for goats). Goat grazing is a hot issue in the village. It started before the 2013 
flood. It has divided people as some are in favor of letting the grazing continue and others are against it. Those who are against the grazing of goats near two glaciers situated at the back of the village are of the view that flood is because of overgrazing over there. Those who favor goat grazing are of the view it has nothing to do with flood. But the issue is not simple as it involves many hidden motives which are discussed in detail in the next chapter.

Sher Muhammad is also Wakhik, people who migrated from Wakhan, and resident of Golguch. They also call themselves Qaziye. He is among those households who are affected in both the 2013 and 2015 flood. "2015 flood was severe and washed away everything. It was continuous for many days from $15^{\text {th }}$ to $25^{\text {th }}$ July. This year it happened 9 times. Everyone got used to it and no one was expecting it would get so heavy. We all were taking it light though were cautious about it. When it happened in the evening, everyone rushed toward the mountains as some family members were already living in tents at the backside near the mountain. Flash flood isolated us from the rest of the world and that was the bad thing that happened to us. We lived without water for more than a day as the water supply line was also damaged by the flood. Only a very narrow path was available that was not possible to cross to reach another part of the village to get water and other utilities. We all were helpless. The only access was the long steep mountain which was too hard to climb. Both in 2013 and lived in tents for months. In 2015 we lived in tents for more than three months. Flood keeps us worried every summer. I don't have any other place to live or shift to. Some of the families who were affected in two floods and are financially stable shifted to nearby village but that place has no vehicle rout to reach that place"

Once during the discussion, he asked me "why don't you ask me the most important question and that is the basic reason for flash floods that are occurring here."I want you to raise this issue through university and other sources as it is more important than anything else. It will save our lives. The land behind the village is very steep. When goats are grazing there, it breaks the soil that is easy to flash with water. It's mainly because of overgrazing". Sher Muhammad is leading the litigation from one group who is opposing the grazing of goats in upper pastures. More than two hundred people in the village gave money to finance the goats grazing case proceedings.

\section{Conclusion}

The Political/power structure of communities can be the root cause of vulnerability. In the pressure and release model, the two main causes of vulnerability are poverty and political structure but from the study of the selected locale in upper Chitral, it can be concluded that political/ power structure plays the main role. It is not possible to measure the risk factors without understanding the political history of the community especially when the community is isolated and not part of the mainstream political and development structure in nation-states. Political history and power structure provides the basis for analyzing the vulnerability of the communities to natural disasters. Chitral remained a princely state where low-status groups lived on marginal locations. With the increasing frequency of flash floods old political and social structure of the community is unfolded. The effectiveness of mitigation and relief programs for such communities can only be achieved if the political structure of the past and its perpetual effect could be understood.

\section{References}

Marsden, M. (2005). Living Islam: Muslim religious experience in Pakistan's north-west frontier. Cambridge University Press.

Asif, M. K., Haneef, M., Anwar, S. K., \& Tazeem, T. (2013). Debris-flow hazards on tributary junction fans, Chitral, Hindu Kush Range, and Northern Pakistan. Journal of Asian Earth Sciences, 62, 720-733.

Bankoff, G., Frerks, G., Hilhorst, D. (Eds.), (2004). Mapping Vulnerability: Disasters Development and People. Earthscan, London.

Bankoff, G. (2004). The historical geography of disaster:'vulnerability'and 'local knowledge in western discourse. In mapping vulnerability (pp. 44-55). Earthscan, London.

Blaikie, P., Cannon, T., Davis, I., \& Wisner, B. (2004). At-Risk. Natural Hazards, People's Vulnerability, and Disasters. London: Routledge Press.

Blaikie, P., \& Brookfield, H. (Eds.). (1987). Land Degradation and Society. London. Methuen.

Chitral Distt. Admin/ District Disaster Management Unit. (2013). Damage Assessment Report Flash Floods-2013, district Chitral, Government of Khyber Pukhtunkhwa 
Chitral Distt. Admin/ District Disaster Management Unit. (2015). Damage and Need Assessment Report of the Torrential/ Orographic Rains and GLOF Events in July-August 2015, District Chitral, Government of Khyber Pukhtunkhwa.

Flick, U. (Ed.). (2013). The SAGE handbook of qualitative data analysis. Sage.

Ferguson, J. (1999) Expectations of Modernity; Myths and Meanings of Urban Life on the Zambian Copperbelt, University of California Press, Berkeley, Los Angeles and London

Hardt, M \& Negri A. (2001) Empire, Harvard University Press, Cambridge

Hamid, Mir. (2013) Glacier lake outburst floods in Reshun Valley of Pakistan. Fact or Fantasy, accessed October 7, 2020. https://dissidentvoice.org/2013/08/glacier-lake-outburst-floods-inreshun-valley-of-pakistan/

Hewitt, K. (1983). The idea of calamity in a technocratic age. In Interpretations of calamity from the viewpoint of human ecology edited by Kenneth Hewitt, 3-32. Winchester, Mass.: Allen \& Unwin.

IUCN Pakistan (2004). Chitral: A Study in Statecraft (1320-1969). Karachi: IUCN Pakistan

Lees, S and Batesss, D (1990) 'The ecology of cumulative change', in E Moran (Ed) The

Ecosystem Approach in Anthropology, University of Michigan Press, Ann Arbor

Middleton, N., \& O'Keefe, P. (1998). Disaster and development: the politics of humanitarian aid. Pluto Press.

Mulk, Hisamul. 1971. 'Notes on the history of Chitral.' Manuscript.

Oliver-Smith, A (1979). 'The Yungay avalanche of 1970: Anthropological perspectives on disaster and social change', Disasters, 3(1): 95-101

Oliver-Smith, A (1986). Disaster context and causation: An overview of changing perspectives in disaster research', in A Oliver-Smith (Ed) Natural Disasters and Cultural Responses, College of William and Mary, Williamsburg, pp1-38

Rehman, G. (2015). GLOF Risk and Reduction Approaches in Pakistan. In Disaster Risk Reduction Approaches in Pakistan (pp. 217-237). Springer, Tokyo.

Richardson, S. D., \& Reynolds, J. M. (2000). An overview of glacial hazards in the Himalayas. Quaternary International, 65, 31-47.

Riaz, S., Ali, A., \& Baig, M. N. (2014). Increasing risk of glacial lake outburst floods as a consequence of climate change in the Himalayan region. Jàmbá: Journal of Disaster Risk Studies, 6(1), 1-7.

Sökefeld, M. (2012). Exploring the Link between Natural Disasters and Politics: Case Studies of Pakistan and Peru. Scrutiny, Journal of International and Pakistan Studies 5-6: 1-32.

The People of Reshun. (2020, September 01). Although, the volunteers of different outlets are serving the humanity in Reshun and other flood-affected areas very well, but we the people of Reshun Gol are still waiting..... [Facebook Status Update]. Retrieved from https://web.facebook.com/permalink.php?story_fbid=2721019018111950\&id=155892637098 7893

Wisner, B. (1976). Man-made famine in Eastern Kenya: the interrelationship of environment and development. Discussion Paper 96. Institute of Development Studies, University of Sussex.

Wisner, B. 1978. The Human Ecology of Drought in Eastern Kenya. Ph.D. Thesis, Graduate School of Geography, Clark University.

Zakirin, Zakir Ahmed. (2020, September 2020). Sir, for your kind information. I myself witness the two days visit of focus volunteers with first aid kits and two groups have worked in restoration...........[Facebook Status Update]. Retrieved from https://web.facebook.com/ permalink.php?story_fbid=2721019018111950\&id=1558926370987893 